\title{
Comparison of infiltration models in NIT Kurukshetra campus
}

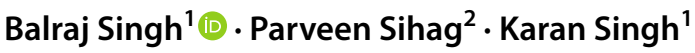

Received: 31 May 2017 / Accepted: 10 April 2018 / Published online: 20 April 2018

(c) The Author(s) 2018

\begin{abstract}
The aim of the present investigation is to evaluate the performance of infiltration models used to calculate the infiltration rate of the soils. Ten different locations were chosen to measure the infiltration rate in NIT Kurukshetra. The instrument used for the experimentation was double ring infiltrometer. Some of the popular infiltration models like Horton's, Philip's, Modified Philip's and Green-Ampt were fitted with infiltration test data and performance of the models was determined using NashSutcliffe efficiency (NSE), coefficient of correlation (C.C) and Root mean square error (RMSE) criteria. The result suggests that Modified Philip's model is the most accurate model where values of C.C, NSE and RMSE vary from 0.9947-0.9999, $0.9877-0.9998$ to $0.1402-0.6913(\mathrm{~mm} / \mathrm{h})$, respectively. Thus, this model can be used to synthetically produce infiltration data in the absence of infiltration data under the same conditions.
\end{abstract}

Keywords Infiltration rate $\cdot$ Double ring infiltrometer $\cdot$ Coefficient of correlation $\cdot$ Nash-Sutcliffe efficiency $\cdot$ Root mean square error

\section{Introduction}

Infiltration of water through soils is a natural process. It is a key component of the hydrological cycle. Infiltration is the process of entering water through top surface of the soil. The actual amount of water percolating into the soil at any time is known as the infiltration rate (Haghighi et al. 2010). Infiltration is related to groundwater recharge and surface runoff (Uloma et al. 2014). It also helps in designing of irrigation, drainage and water supply systems, flood control measures, landslides and many other natural and man-made processes (Igbadun and Idris 2007). Various models (Philip's, Kostiakov, US-Soil Conservation Service (SCS), Horton, Holton etc.) have been developed to evaluate the infiltration.

Balraj Singh

balrajzinder@gmail.com

Parveen Sihag

parveen12sihag@gmail.com

Karan Singh

karans72@gmail.com

1 Civil Engineering Department, NIT Hamirpur, Hamirpur 177005, India

2 Civil Engineering Department, NIT Kurukshetra, Thanesar 136119, India
Many infiltration models have been evolved to evaluate hydrologic process from about 1911 (Green and Ampt 1911; Williams et al. 1998). These models were presented and summarized systematically and extensively by Williams et al. (1998). Several researchers were able to successfully compare and evaluate those available soil-infiltration models in different frameworks under field conditions (Mbagwu 1995; Mishra and Singh 1999; Shukla et al. 2003; Chahinian et al. 2005; Dashtaki et al. 2009).

Mirzaee et al. (2013) thought about the capacity of eight diverse infiltration models (i.e. Green and Ampt, Philip, Horton, Kostiakov, Modified Kostiakov, Swartzendruber, Revised Modified Kostiakov models and SCS (US-Soil Conservation Service)) which were assessed by least squares fitting to measured soil infiltration. Sihag et al. (2017a) have compared the various infiltration models (Kostiakov, SCS, Novel model and Modified Kostiakov) for the NIT Kurukshetra campus. Novel model was most suited as compared to others with field infiltration data.

Sihag et al. (2017b, c) and Singh et al. (2017) utilized the various soft computing techniques to predict the infiltration rate of the soil. The objective of the present investigation is to determine the model parameters and find out the best suitable model for the soil of below mentioned study area. 


\section{Study area}

NIT Kurukshetra is one of the reputed institutes of India situated in Kurukshetra. Geographic coordinates of the institute is $29.9655^{\circ} \mathrm{N}, 76.7106^{\circ} \mathrm{E}$ which comes under Upper Ghaggar Basin. Generally, the major soil type in Kurukshetra is clayey loam and sandy loam. The details of the ten locations, which were selected to find out the infiltration rate, are described in Fig. 1.

\section{Methodology}

The instrument used for find out the infiltration rates was Double ring infiltrometer (ASTM 2009). As shown in Fig. 2, the double ring infiltrometer has two parts: one was outer ring whose diameter was $450 \mathrm{~mm}$, and second was inner ring whose diameter is $300 \mathrm{~mm}$. The rings of infiltrometer were driven $100 \mathrm{~mm}$ depth into the soil. The hammer should strike uniformly on steel plate which is placed on the top of the ring without disturbing the top soil surface. The water

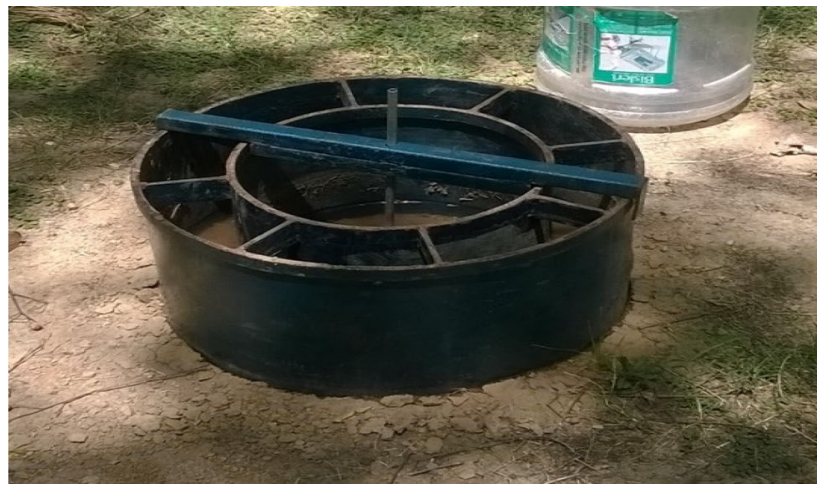

Fig. 2 Double ring Infiltrometer

was filled at the same level of both rings. The profundity of water in the infiltrometer was recorded at regular interims until the steady infiltration rate was achieved. The soil sample (about 100-150 g) for calculating moisture content was collected from a site nearest to the location chosen for experimentation.
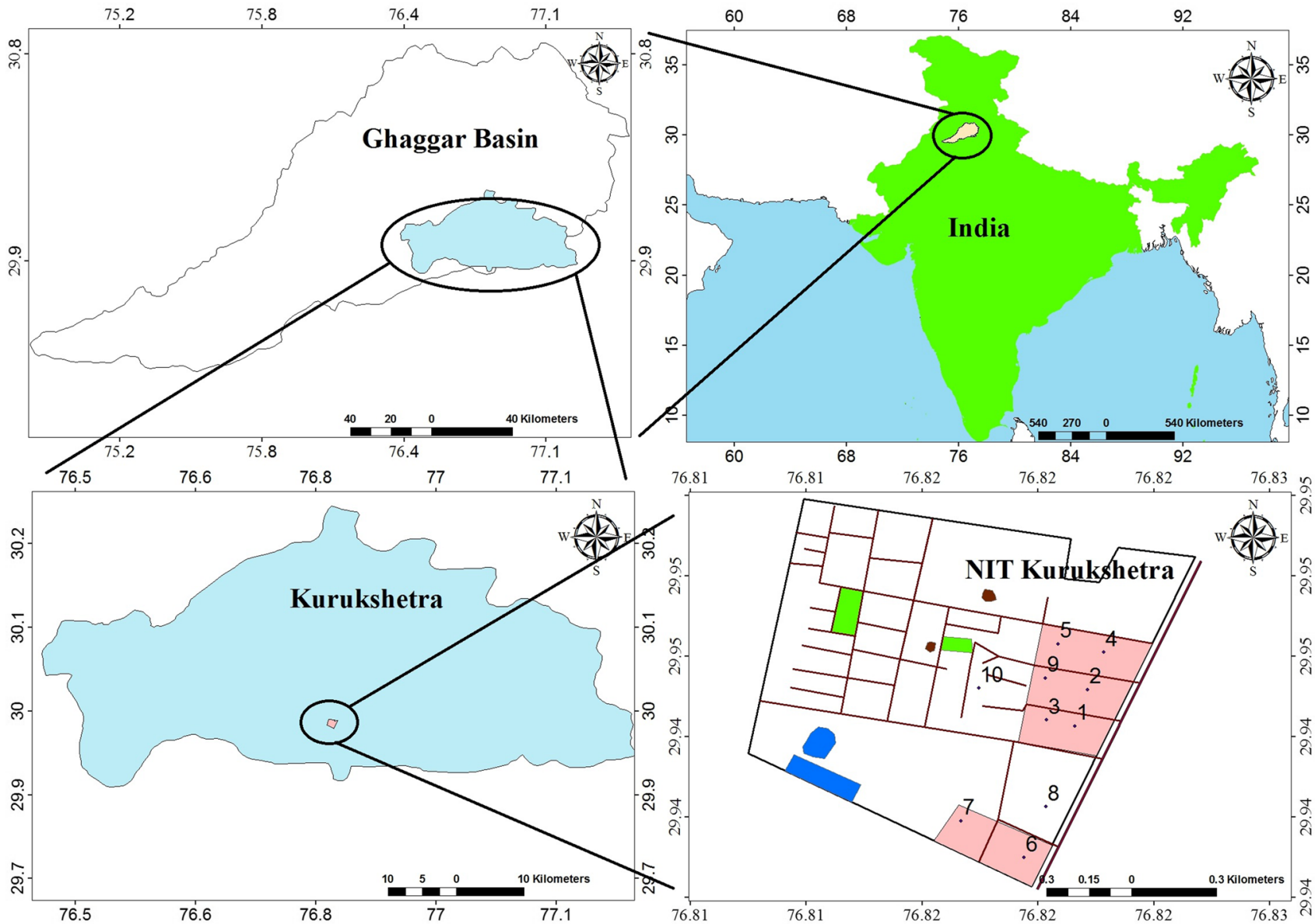

Fig. 1 Location map of study area 
Fig. 3 Comparison of the field infiltration rate with various models estimated infiltration rate for the study area (site no. 1-10)
Test no. 1

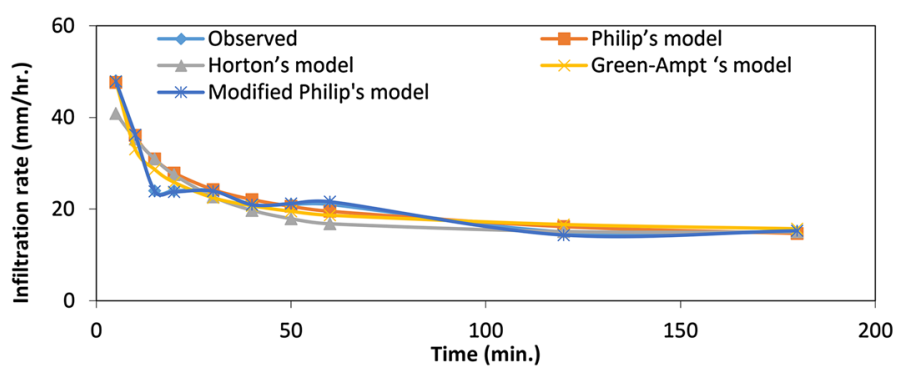

Test no. 2

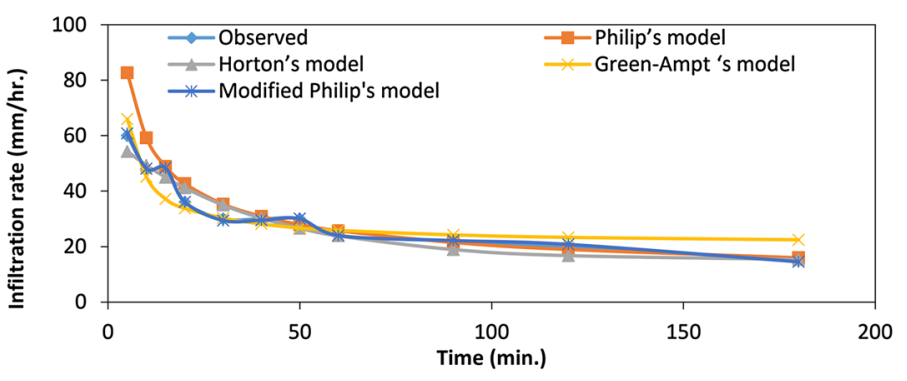

Test no. 3

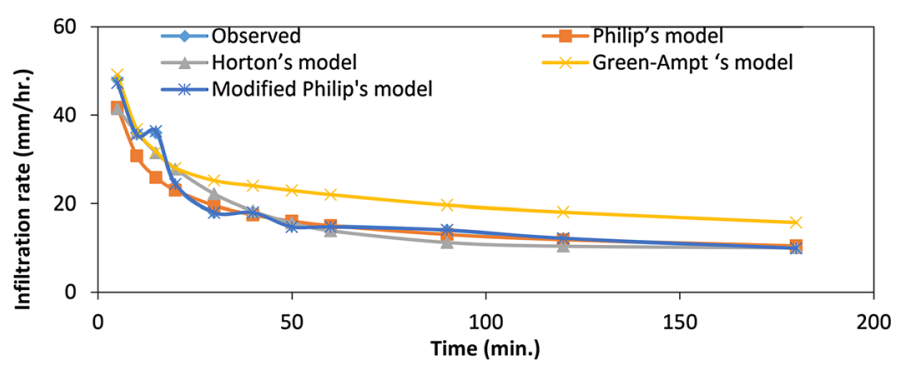

Test no. 4

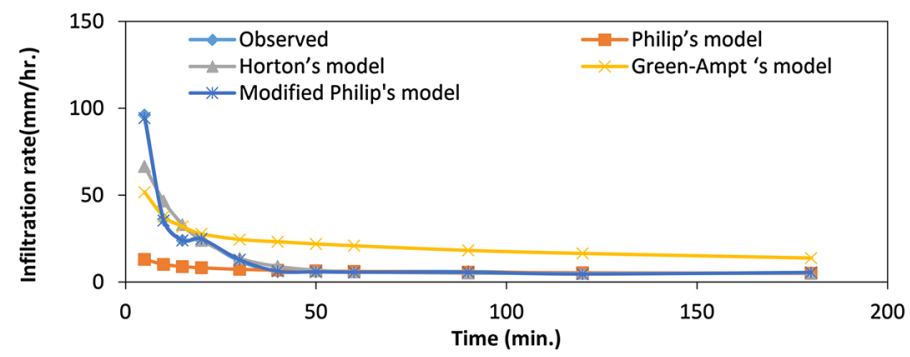

Test no. 5

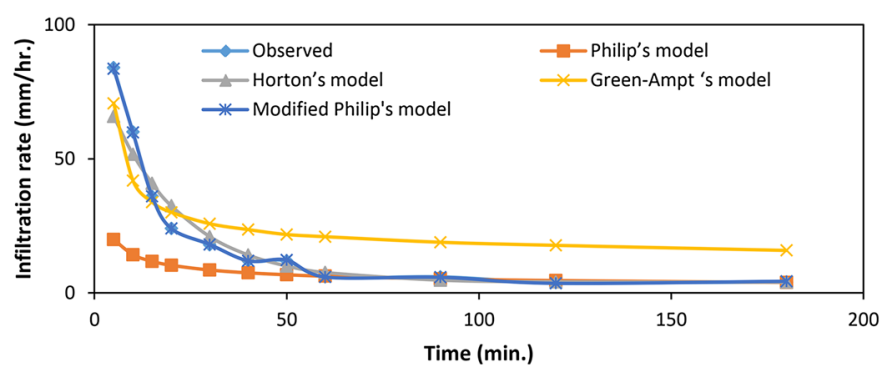


Fig. 3 (continued)

Test no. 6

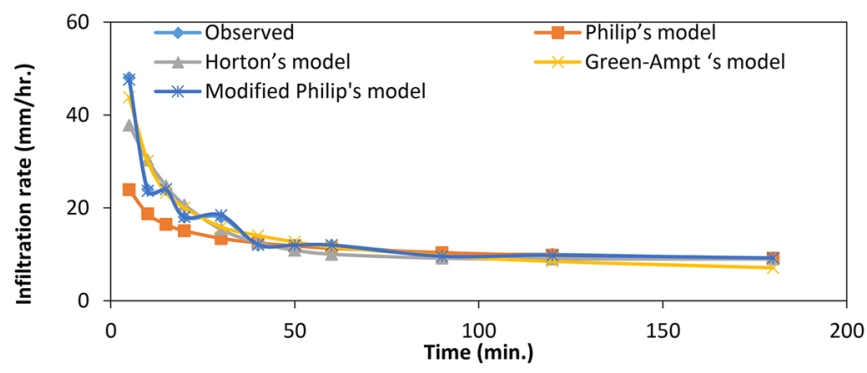

Test no. 7

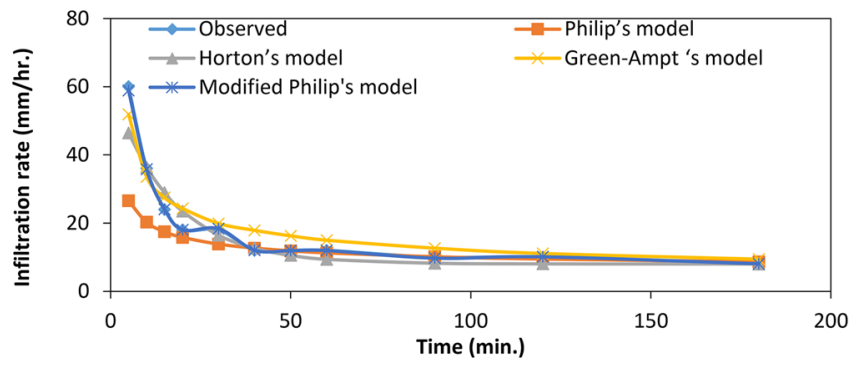

Test no. 8

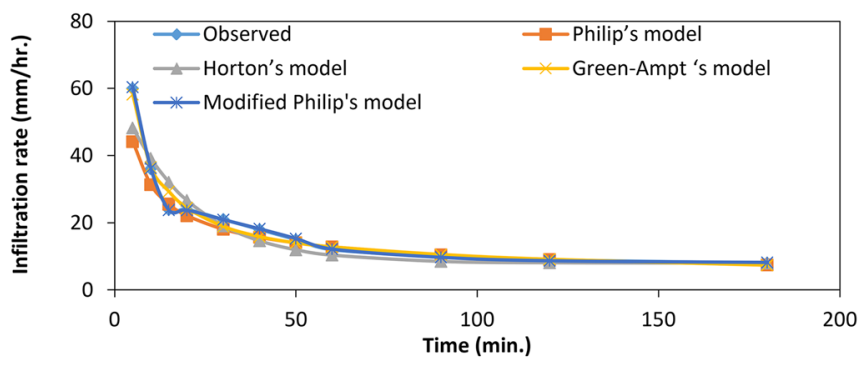

Test no. 9

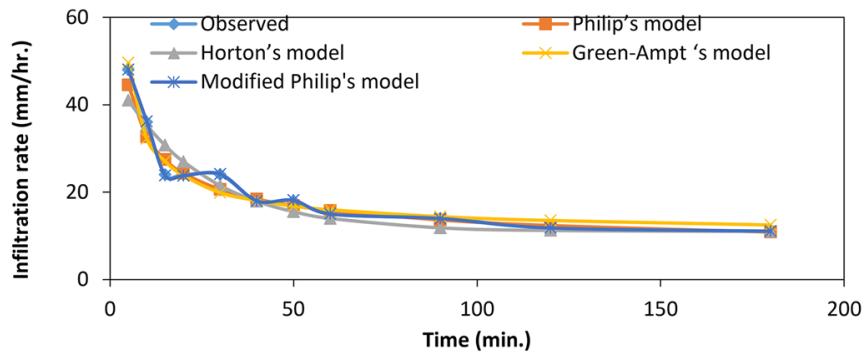

Test no. 10

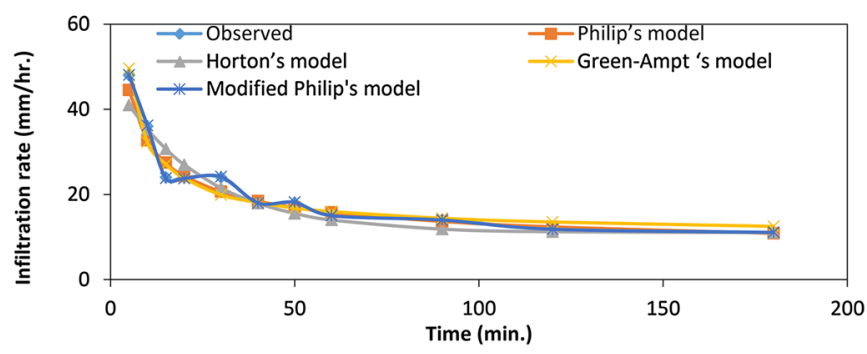


Table 1 Detail of initial, final infiltration rates and moisture contents of ten locations

\begin{tabular}{lllllllllll}
\hline Test no. & 1 & 2 & 3 & 4 & 5 & 6 & 7 & 8 & 9 & 10 \\
\hline Initial infiltration rate $(\mathrm{mm} / \mathrm{h})$ & 48 & 60 & 48 & 96 & 84 & 48 & 60 & 60 & 48 & 48 \\
Final infiltration rate $(\mathrm{mm} / \mathrm{h})$ & 15 & 15 & 10 & 5 & 4 & 9 & 8 & 8 & 11 & 11 \\
Moisture content $(\%)$ & 3.44 & 2.65 & 1.93 & 7.98 & 7.65 & 3.51 & 3.40 & 4.20 & 5.27 & 3.83 \\
\hline
\end{tabular}

$m=\left(m_{0}-m_{\mathrm{c}}\right) e^{-k t}+m_{\mathrm{c}}$,

\section{Infiltration models and parameters}

In this study, four popular infiltration models were selected and model parameters are driven by using the data obtained from field measurement.

\section{Philip's model}

Philip's (1957) model expressed as follows:

$m=\frac{1}{2} S t^{-0.5}+A$,

where $m$ is the infiltration rate $\left(\mathrm{LT}^{-1}\right) ; S$ is the $\left(\mathrm{LT}^{-0.5}\right) ; A$ is the soil parameter related to the transmission of water through the soil or gravity force $\left(\mathrm{LT}^{-1}\right)$, and $t$ is time (T).

\section{Modified Philip's model}

The modified model of Philip (Su 2010) is defined as

$m=\frac{1}{2} S t^{-\frac{\beta}{2}}+A$,

where $\beta$ is an empirical constant.

\section{Horton's model}

The Horton's infiltration model (Horton 1941) is expressed as follows: where $m_{\mathrm{c}}$ is the steady infiltration rate $\left(\mathrm{LT}^{-1}\right) ; m_{0}$ is the initial infiltration rate $\left(\mathrm{LT}^{-1}\right)$, and $t$ is time (T). $k$ is the infiltration decay factor.

\section{Green-Ampt's model}

There are many equations derived from applying Darcy's law to the wetted zone in the soil, using the fact that a distinct wetting front exists. Green and Ampt (1911) were the first with this approach, and their equation is in the form of

$m=K_{\mathrm{s}}+\left(K_{\mathrm{s}} \cdot(\cdot s) / M\right.$,

where $s$ is the capillary suction at the wetting front; $K_{\mathrm{s}}$ is saturated hydraulic conductivity, and $M$ is the cumulative infiltration (L). The equation may be written as follows:

$m=b+c / M$,

where $b=K_{\mathrm{s}}$ and $c=\mathrm{K}_{\mathrm{s}} \cdot(\cdot \mathrm{s})$.

\section{Estimation and inter-comparison of models parameters}

Comparison of difference between the predicted infiltration rate values and measured values was done to evaluate the infiltration rate. Those model performances are addressed below:
Table 2 Parameters of the selected infiltration model

\begin{tabular}{|c|c|c|c|c|c|c|c|c|}
\hline \multirow[t]{3}{*}{ Test no. } & \multicolumn{8}{|c|}{ Equation parameters } \\
\hline & \multicolumn{2}{|c|}{ Philip's model } & \multirow{2}{*}{$\begin{array}{l}\text { Hortron's model } \\
k\end{array}$} & \multicolumn{2}{|c|}{$\begin{array}{l}\text { Green-Ampt } \\
\text { Model }\end{array}$} & \multicolumn{3}{|c|}{ Modified Philip's model } \\
\hline & $S$ & $A$ & & $b$ & $c$ & $S$ & $\beta$ & $A$ \\
\hline 1 & 176.96 & 8.08 & 0.048 & 13.20 & 138.75 & 2.547 & -1.452 & 0.046 \\
\hline 2 & 357.91 & 2.62 & 0.027 & 19.15 & 233.98 & 7.186 & -1.178 & -5.063 \\
\hline 3 & 167.85 & 4.21 & 0.038 & 8.47 & 174.92 & 3.830 & -1.229 & -0.449 \\
\hline 4 & 42.91 & 3.35 & 0.078 & 0.34 & 410.75 & 6.027 & -0.833 & 3.805 \\
\hline 5 & 85.83 & 0.70 & 0.052 & 1.62 & 483.61 & 230.227 & -0.106 & -117.905 \\
\hline 6 & 79.31 & 6.20 & 0.060 & 2.73 & 164.51 & 2.297 & -1.329 & 1.030 \\
\hline 7 & 96.05 & 5.06 & 0.060 & 3.082 & 243.88 & 2.945 & -1.235 & 2.113 \\
\hline 8 & 196.89 & 0.11 & 0.052 & 0.22 & 289.88 & 8.256 & -0.910 & -4.103 \\
\hline 9 & 180.66 & 4.12 & 0.042 & 9.08 & 162.12 & 4.110 & -1.221 & -1.564 \\
\hline 10 & 180.66 & 4.12 & 0.042 & 9.08 & 162.12 & 4.110 & -1.221 & -1.564 \\
\hline
\end{tabular}

$S$ sorptivity $\left(\mathrm{mm} \mathrm{min}^{-0.5}\right), A$ transmissivity $\left(\mathrm{mm} \mathrm{min}^{-1}\right), b$ and $c$ equation parameters, $k$ infiltration decay factor 
Table 3 Performance evaluation parameters of infiltration models

\begin{tabular}{|c|c|c|c|c|c|}
\hline Sr. no. & Test no. & Philip's model & Horton's model & $\begin{array}{l}\text { Green-Ampt } \\
\text { model }\end{array}$ & $\begin{array}{l}\text { Modified } \\
\text { Philip's model }\end{array}$ \\
\hline \multicolumn{6}{|c|}{ (i) Coefficient of correlation (C.C) } \\
\hline 1 & 1 & 0.975 & 0.967 & 0.931 & 0.9997 \\
\hline 2 & 2 & 0.978 & 0.969 & 0.952 & 0.9997 \\
\hline 3 & 3 & 0.936 & 0.942 & 0.942 & 0.9997 \\
\hline 4 & 4 & 0.983 & 0.974 & 0.941 & 0.9947 \\
\hline 5 & 5 & 0.964 & 0.938 & 0.948 & 0.9995 \\
\hline 6 & 6 & 0.971 & 0.953 & 0.983 & 0.9996 \\
\hline 7 & 7 & 0.984 & 0.947 & 0.967 & 0.9994 \\
\hline 8 & 8 & 0.985 & 0.952 & 0.993 & 0.9997 \\
\hline 9 & 9 & 0.985 & 0.952 & 0.980 & 0.9999 \\
\hline 10 & 10 & 0.985 & 0.952 & 0.980 & 0.9999 \\
\hline Average & & 0.975 & 0.955 & 0.964 & 0.9992 \\
\hline \multicolumn{6}{|c|}{ (ii) Nash-Sutcliffe efficiency (NSE) } \\
\hline 11 & 1 & 0.924 & 0.842 & 0.947 & 0.9995 \\
\hline 12 & 2 & 0.621 & 0.933 & 0.866 & 0.9994 \\
\hline 13 & 3 & 0.887 & 0.931 & 0.782 & 0.9993 \\
\hline 14 & 4 & -0.096 & 0.853 & 0.548 & 0.9876 \\
\hline 15 & 5 & -0.044 & 0.924 & 0.771 & 0.9989 \\
\hline 16 & 6 & 0.464 & 0.872 & 0.942 & 0.9992 \\
\hline 17 & 7 & 0.406 & 0.893 & 0.917 & 0.9978 \\
\hline 18 & 8 & 0.872 & 0.892 & 0.981 & 0.9994 \\
\hline 19 & 9 & 0.961 & 0.902 & 0.959 & 0.9998 \\
\hline 20 & 10 & 0.961 & 0.902 & 0.959 & 0.9998 \\
\hline Average & & 0.596 & 0.895 & 0.867 & 0.9981 \\
\hline \multicolumn{6}{|c|}{ (iii) Root mean square error (RMSE) $(\mathrm{mm} / \mathrm{h})$} \\
\hline 21 & 1 & 2.609 & 3.767 & 2.166 & 0.3217 \\
\hline 22 & 2 & 3.989 & 3.119 & 3.600 & 0.4496 \\
\hline 23 & 3 & 27.084 & 9.897 & 8.703 & 0.3151 \\
\hline 24 & 4 & 25.427 & 6.855 & 17.38 & 0.6913 \\
\hline 25 & 5 & 7.941 & 3.870 & 11.89 & 0.2450 \\
\hline 26 & 6 & 11.418 & 4.846 & 2.692 & 0.2583 \\
\hline 27 & 7 & 5.188 & 4.763 & 4.254 & 0.3671 \\
\hline 28 & 8 & 2.104 & 3.331 & 0.315 & 0.2537 \\
\hline 29 & 9 & 2.104 & 3.331 & 2.139 & 0.1402 \\
\hline 30 & 10 & 2.104 & 3.331 & 2.139 & 0.1402 \\
\hline Average & & 8.997 & 4.711 & 5.528 & 0.3182 \\
\hline
\end{tabular}

\section{Coefficient of correlation}

Coefficient of correlation is a measure of the linear regression between the predicted values and the targets of models. The coefficient of correlation (C.C) is computed as

C.C $=\frac{z \sum a b-\left(\sum a\right)\left(\sum b\right)}{\sqrt{z\left(\sum a^{2}\right)-\left(\sum a\right)^{2}} \sqrt{z\left(\sum b^{2}\right)-\left(\sum b\right)^{2}}}$.

\section{Nash-Sutcliffe efficiency}

The Nash-Sutcliffe efficiency (NSE) (Nash and Sutcliffe 1970) has value between $-\infty$ and 1 . Its value is defined by

$\mathrm{NSE}=1-\frac{\sum_{i=1}^{z}\left(a_{i}-b_{i}\right)^{2}}{\sum_{i=1}^{z}\left(a_{i}-\bar{a}\right)^{2}}$. 


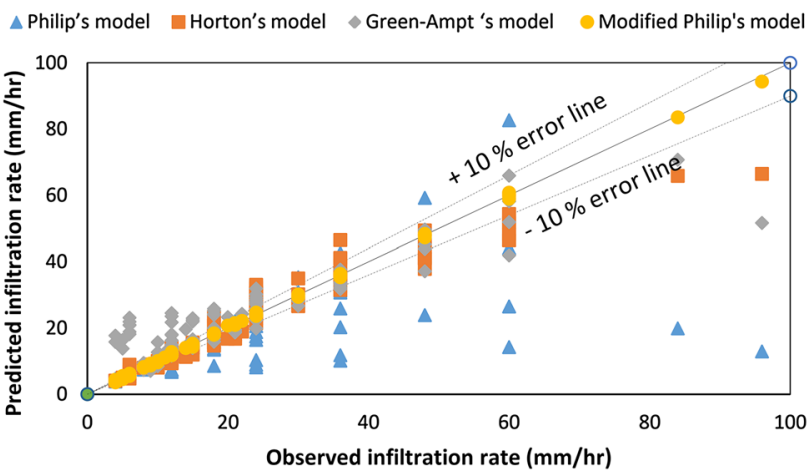

Fig. 4 Observed infiltration rate and predicted infiltration rate of various models

\section{Root mean square error (RMSE)}

This method exaggerates the prediction error-the difference between prediction value and actual value. The root mean squared error (RMSE) is evaluated by

RMSE $=\sqrt{\frac{1}{z}\left(\sum_{i=1}^{z}\left(a_{i}-b_{i}\right)^{2}\right)}$,

where $a$ is the calculated and $b$ is observed values of infiltration rate and $z$ is the number of observations.

\section{Result and discussion}

Infiltration tests were carried out within the field in order to deal with the spatial variability of infiltration rate. Based on the field tests at 10 different locations in NIT Kurukshetra area, results were analysed and individual infiltration curves have been developed in Fig. 3. Table 1 shows the values of initial infiltration rate, final infiltration rate and moisture content of soil sample of various locations. The initial infiltration rate, final infiltration rate and moisture contents fluctuate from $96-48 \mathrm{~mm} / \mathrm{h}, 15-11 \mathrm{~mm} / \mathrm{h}$ to $7.98-1.93 \%$, respectively, for the study area.

A number of infiltration models are projected to find out field infiltration rates. The projected models Philip's, Horton's, Green-Ampt and Modified Philip's were chosen for evaluation in the study. To study these models, actual field infiltration data have been used. Attempt was made to evaluate these infiltration equations on the basis of experimental data of the study area and to obtain numerical values for the parameters of the models (Table 2). For the analysis of infiltration data and find out the parameters of the above model using least square techniques, XLSTAT software has been used.
Infiltration models were evaluated using C.C, NSE and RMSE methods. The most suitable model was selected on the basis of maximum values of C.C and NSE and RMSE criteria. Findings are summarized in Table 3.

The computed average values of C.C values were 0.975 $0.955,0.964$ and 0.9992 , NSE were $0.596,0.895,0.868$ and 0.998 , and those RMSE values were 8.997, 4.711, 5.528, and $0.3182 \mathrm{~mm} / \mathrm{h}$ for Philip's, Horton's, Green-Ampt and Modified Philip's model, respectively.

Figure 4 provides the information about observed infiltration rate and predicted values of infiltration rate of the above-mentioned models and suggests that all the values of Modified Philip's model are lying inside the $\pm 10 \%$ error band from the line of perfect agreement than the other infiltration models (Horton's model, Green-Ampt model and Philip's model). Similarly, comparison of the C.C, NSE, RMSE suggests a better performance by Modified Philip's model in comparison to Philip's, Horton's and Green-Ampt model. Thus, Modified Philip's model performs best amid all models mentioned above for the study area, and hence, this model was used to assess the infiltration rate of this study area.

\section{Conclusion}

Infiltration is an important parameter in the hydrological cycle and one of the thrust areas in hydrology. Infiltration rate data for different soils are essential for understanding of the rainfall-runoff process and for planning and design of water resource systems. While comparing infiltration models with field data, it is observed that infiltration rate versus time plots for field data and modelled data do not accurately match; but the Modified Philip's model is much closer to observed field data having C.C, NSE and RMSE values of $0.9992,0.9981$ and $0.3182(\mathrm{~mm} / \mathrm{h})$, respectively. It can thus be used to synthetically generate infiltration data in the absence of observed infiltration data for NIT Kurukshetra, Haryana (India).

Open Access This article is distributed under the terms of the Creative Commons Attribution 4.0 International License (http://creativeco mmons.org/licenses/by/4.0/), which permits unrestricted use, distribution, and reproduction in any medium, provided you give appropriate credit to the original author(s) and the source, provide a link to the Creative Commons license, and indicate if changes were made.

\section{References}

ASTM (2009) Standard test method for infiltration rate of soils in field using double-ring infiltrometer. D3385-09, West Conshohocken, PA

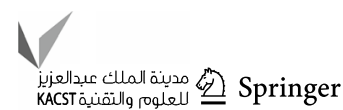


Chahinian N, Moussa R, Andrieux P, Voltz M (2005) Comparison of infiltration models to simulate flood events at the field scale. J Hydrol 306(1):191-214

Dashtaki SG, Homaee M, Mahdian MH, Kouchakzadeh M (2009) Sitedependence performance of infiltration models. Water Resour Manag 23(13):2777-2790

Green WH, Ampt GA (1911) Studies in soil physics. J Agric Sci 4:1-24

Haghighi F, Gorji M, Shorafa M, Sarmadian F, Mohammadi MH (2010) Evaluation of some infiltration models and hydraulic parameters. Span J Agric Res 8(1):210-217

Horton RE (1941) An approach toward a physical interpretation of infiltration-capacity. Soil Sci Soc Am J 5(C):399-417

Igbadun HE, Idris UD (2007) Performance evaluation of infiltration models in a hydromorphic soil. Niger J Soil Environ Res 7(1):53-59

Mbagwu JSC (1995) Testing the goodness of fit of infiltration models for highly permeable soils under different tropical soil management systems. Soil Tillage Res 34(3):199-205

Mirzaee S, Zolfaghari AA, Gorji M, Dyck M, Ghorbani Dashtaki S (2013) Evaluation of infiltration models with different numbers of fitting in different soil texture classes. Arch Agron Soil Sci 2013:1-13

Mishra SK, Singh VP (1999) Another look at SCS-CN method. J Hydrol Eng 4(3):257-264

Nash JE, Sutcliffe JV (1970) River flow forecasting through conceptual models part I-a discussion of principles. J Hydrol 10(3):282-290

Philip JR (1957) The theory of infiltration: 1 . The infiltration equation and its solution. Soil Sci 83(5):345-358

Shukla MK, Lal R, Unkefer P (2003) Experimental evaluation of infiltration models for different land use and soil management systems. Soil Sci 168(3):178-191
Sihag P, Tiwari NK, Ranjan S (2017a) Estimation and inter-comparison of infiltration models. Water Sci 31(1):34-43

Sihag P, Tiwari NK, Ranjan S (2017b) Modelling of infiltration of sandy soil using gaussian process regression. Model Earth Syst Environ 3(3):1091-1100

Sihag P, Tiwari NK, Ranjan S (2017c) Prediction of unsaturated hydraulic conductivity using adaptive neuro-fuzzy inference system (ANFIS). ISH J Hydraul Eng. https://doi.org/10.1080/09715 010.2017.1381861

Singh B, Sihag P, Singh K (2017) Modelling of impact of water quality on infiltration rate of soil by random forest regression. Model Earth Syst Environ 3(3):999-1004

Su N (2010) Theory of infiltration: infiltration into swelling soils in a material coordinate. J Hydrol 395(1):103-108

Uloma AR, Samuel AC, Kingsley IK (2014) Estimation of Kostiakov's infiltration model parameters of some sandy loam soils of Ikwuano-Umuahia, Nigeria. Open Trans Geosci 1(1):34-38

Williams JR, Ying O, Chen JS, Ravi V (1998) Estimation of infiltration rate in the vadose zone: application of selected mathematical models, vol 2 (No. PB-98-147317/XAB). ManTech Environmental Technology, Inc., Research Triangle Park, NC (United States); Dynamac Corp., Ada, OK (United States); National Risk Management Research Lab., Subsurface Protection and Remediation Div., Ada, OK (United States)

Publisher's Note Springer Nature remains neutral with regard to jurisdictional claims in published maps and institutional affiliations. 